\title{
Current Status and Future Prospects of White Root Rot Management in Pear Orchards: A Review
}

*Corresponding author

Tel: +82-61-330-1562

Fax: +82-61-330-1533

E-mail: shj2992@korea.kr

${ }^{\dagger}$ These authors contributed

equally to this work.
Received July 17, 2021

Revised August 14, 2021

Accepted August 31, 2021

\author{
Shailesh S. Sawant ${ }^{\dagger}$, Eu Ddeum Choi ${ }^{\dagger}$, Janghoon Song, and Ho-Jin Seo* \\ Pear Research Institute, National Institute of Horticultural \& Herbal Science, Naju 58216, Korea
}

\begin{abstract}
The current social demand for organic, sustainable, and eco-friendly approaches for farming, while ensuring the health and productivity of crops is increasing rapidly. Biocontrol agents are applied to crops to ensure biological control of plant pathogens. Research on the biological control of white root rot disease caused by a soil-borne pathogen, Rosellinia necatrix, is limited in pears compared to that in apple and avocado. This pathogenic fungus has an extensive host range, and symptoms of this disease include rotting of roots, yellowing and falling of leaves, wilting, and finally tree death. The severity of the disease caused by R. necatrix, makes it the most harmful fungal pathogen infecting the economical fruit tree species, such as pears, and is one of the main limiting factors in pear farming, with devastating effects on plant health and yield. In addition to agronomic and cultural practices, growers use chemical treatments to control the disease. However, rising public concern about environmental pollution and harmful effects of chemicals in humans and animals has facilitated the search for novel and environmentally friendly disease control methods. This review will briefly summarize the current status of biocontrol agents, ecofriendly methods, and possible approaches to control disease in pear orchards.
\end{abstract}

Keywords: Biocontrol, Pear orchards, Soil borne disease, Rosellinia necatrix, Virocontrol

\section{Introduction}

Rosellinia necatrix Berl. ex Prill. (anamorph Dematophora necatrix R. Hartig), a necrotrophic phytopathogenic fungus that threatens myriad of species, is reported in different countries worldwide (Kulshrestha et al., 2014; Narváez et al., 2020). Its host range comprising more than 400 plant species has been listed by the USDA-ARS (United States Department of Agriculture, Agricultural Research Service, http://nt.arsgrin.gov/fungaldatabases/index.cfm), which is frequently updated because several new hosts are continuously identified and added to the database. The fungus $R$. necatrix, which belongs to the Xylariaceae family, is a soil-borne fungus that

Research in Plant Disease

pISSN 1598-2262, elSSN 2233-9191

www.online-rpd.org causes white root rot, which seriously damages the roots of economically important plants worldwide (Kulshrestha et al., 2014). R. necatrix infects both the surfaces of roots and the tissue under the bark in a broad range of economically important crops, such as cotton, nuts, apples, cherries, avocados, and pears (Eguchi et al., 2008; Lee et al., 2020; Pérez-Jiménez, 2006; Ten Hoopen and Krauss, 2006). R. necatrix-mediated disease cause physically devastating symptoms in fruit trees, which makes it one of the most significant agricultural problems in the world (Kim et al., 2019). White root rot disease results in varying degrees of canopy decline, followed by leaf drop, wilting, and eventually the death of infected plants (Kim et al., 2019). Moreover, the pathogen can survive and remain active on the residues of susceptible crops such as olives, grapevines, and almonds for many years (Cazorla et al., 2006). R. necatrix can survive as saprophytes on dead roots and other plant debris in the soil, although fresh vegetable 
debris rich in cellulose is required for its continued survival. Under laboratory conditions, the pathogen survived on pear branches for a period of 18 months and died when the cellulose content decreased to $50 \%$ of the initial content (Araki, 1967). R. necatrix spreads in soil via mycelial growth, which proliferates and aggregates on the roots of host plants, and the pathogen may disperse in the soil via direct root-to-root contact between host plants and healthy plants (Pliego et al. 2009).

Currently, R. necatrix is widely dispersed in different hosts and has been detected in temperate, tropical, and subtropical regions in all five continents. It has been detected in countries such as China, South Korea, India, Iran, Pakistan, Australia, Mexico, Dominican Republic, Colombia, Brazil, the Democratic Republic of Congo, and Ethiopia (CABI, 2020). In Korea, this disease is posing a serious problem in pear and apple cultivation. The disease prevalent in both nurseries and orchards is destructive, resulting in substantial loss of yield and quality for apple and pear growers in Korea (Lee et al., 1995, 2006, 2016, 2020).

Pears belong to the genus Pyrus (Rosaceae, Pyrinae), and are commercially important fruit trees. They are one of the oldest plants cultivated by humans. Pear production worldwide is second to that of apples, and the world production for 2020/21 is anticipated to reach over 1.0 million tons to 22.2 million tons. In 2019, 23.9 million tons of pear fruit were produced in over 80 countries (FAOSTAT, http://faostat.fao. org/). Fresh pear fruit is consumed globally and is also found in processed products such as drinks, candy, preserved fruits, and jam. However, irrespective of its health benefits and economic value, the production levels and number of pear orchards have been progressively decreasing. A major reason for low production is the prevalence of diseases that appear at various growth stages and are difficult to manage. White root rot is a major problem that causes tree mortality. This disease is rather destructive as it eradicates the established orchards and causes considerable loss in the nursery. Root rot diseases infect deep in soil, and their management using chemicals is cumbersome and results in pollution. Therefore, the use of eco-friendly methods or bio-agents is a good alternative for managing such diseases. The use of biocontrol agents has received the most attention with respect to ecofriendly disease management, and necessitates implementation in pear orchards. In this review, we provide an overview of biocontrol agents, and available ecofriendly methods that can be used to control disease in pear orchards.

\section{Control of White Root Rot Caused by Rosellinia necatrix}

Controlling white root rot in the field has been proven difficult because of its tolerance and survival under drought conditions, tolerance to a wide range of soil $\mathrm{pH}$, wide host range, and resistance to common fungicides (Khan, 1959). Therefore, to control this pathogen in the field, methods should focus on reducing the impact and spread of disease, which avoids chemicals and utilizes biological control agents $(B C A)$, thereby implementing eco-friendly methods.

\section{Biological Control}

Numerous studies have been published on biological control of white root rot disease caused by $R$. necatrix by exploiting BCA, which has received considerable attention. Relatively few studies have focused on disease control in the field. Traditionally, growers use chemical fungicides to reduce the disease incidence in orchards. However, due to environmental concern, application of different BCA such as fungal antagonist, antagonistic bacteria, and mycoviruses are effective tools against white root rot caused by R. necatrix (Table 1).

\section{Fungal Antagonist}

Various fungal species have been used as biocontrol agents against $R$. necatrix (Table 1). These antagonistic fungi reduce mycelial growth in vitro and decrease disease symptoms caused by $R$. necatrix in different fruit tree crops such as apples, avocados, and apricots (Cruz et al., 2014; Pal et al., 2020; Ruano-Rosa et al., 2018). Among fungal genera investigated as biocontrol agents, Trichoderma has received considerable attention and has been successfully implemented as a BCA against $R$. necatrix in apple orchards (Golafrouz et al., 2020; Pasini et al., 2016; Sztejnberg et al., 1987) and avocado plants (Ruano Rosa and López-Herrera, 2009; Ruano-Rosa et al., 2018). A recent study by Pal et al. (2020) observed that the endophytic fungi Aspergillus aculeatus (strain C2) showed a maximum mycelial inhibition of $81.48 \%$, and Crinipellis tabtim (strain M8) reduced disease incidence by up to $84.95 \%$ under field conditions in apple orchards. Furthermore, nonpathogenic $R$. necatrix isolates $\mathrm{Rn} 12$ and 29 have shown to 
Table 1. Biocontrol agents to control Rosellinia necatrix

\begin{tabular}{|c|c|c|c|c|c|}
\hline & Pathogen & Tree/Crop & $\begin{array}{l}\text { Controlled } \\
\text { condition }\end{array}$ & $\begin{array}{l}\text { Field } \\
\text { trial }\end{array}$ & Reference \\
\hline \multicolumn{6}{|l|}{ Control agents: fungi } \\
\hline Trichoderma harzianum & Rosellinia necatrix & Apple & Yes & Yes & Sztejnberg et al. (1987) \\
\hline Entoleuca sp. & Rosellinia necatrix & Avocado & Yes & No & $\begin{array}{l}\text { Arjona-López and } \\
\text { López-Herrera (2021) }\end{array}$ \\
\hline Trichoderma spp. & Rosellinia necatrix & Avocado & Yes & No & Ruano-Rosa et al. (2018) \\
\hline T. harzianum T-22 & Rosellinia necatrix & Loquat & Yes & No & Takahashi et al. (2020) \\
\hline Trichoderma atroviride SC1 & Rosellinia necatrix & Apple & Yes & No & Pasini et al. (2016) \\
\hline Trichoderma spp. & Rosellinia necatrix & Avocado & Yes & No & $\begin{array}{l}\text { Ruano Rosa and } \\
\text { López-Herrera (2009) }\end{array}$ \\
\hline $\begin{array}{l}\text { Rosellinia necatrix isolates } \\
\quad(\mathrm{Rn} 12 \text { and } \mathrm{Rn} 29)\end{array}$ & Rosellinia necatrix & Avocado & Yes & No & $\begin{array}{l}\text { Arjona-López and } \\
\text { López-Herrera (2020) }\end{array}$ \\
\hline Gigaspora margarita & Rosellinia necatrix & Apricot & Yes & No & Cruz et al. (2014) \\
\hline \multicolumn{6}{|l|}{ Control agents: mycovirus } \\
\hline $\begin{array}{l}\text { R.necatrix megabirnavirus } 1 \\
\text { (RnMBV1) }\end{array}$ & Rosellinia necatrix & Apple & Yes & No & Chiba et al. (2009) \\
\hline R. necatrix hypovirus 2 (RnHV2) & Rosellinia necatrix & Avocado & Yes & No & Arjona-López et al. (2021) \\
\hline Reovirus & Rosellinia necatrix & Apple & Yes & No & Kanematsu et al. (2004) \\
\hline & & & & & \\
\hline $\begin{array}{c}\text { Pseudomonas putida AVO102 Pseudo } \\
\text { monas pseudoalcaligenes AVO110 }\end{array}$ & Rosellinia necatrix & Avocado & Yes & No & Pliego et al. (2007) \\
\hline Bacillus thuringiensis $\mathrm{C} 25$ & Rosellinia necatrix & NA & NA & NA & Kim et al. (2019) \\
\hline $\begin{array}{l}\text { Pseudomonas chlororaphis and } \\
\text { Bacillus subtilis }\end{array}$ & Rosellinia necatrix & Avocado & Yes & NA & Arjona-López et al. (2019) \\
\hline $\begin{array}{l}\text { P. chlororaphis PCL1606 and } \\
\text { B. subtilis CB115 }\end{array}$ & Rosellinia necatrix & Avocado & Yes & No & $\begin{array}{l}\text { González-Sánchez et al. } \\
\text { (2013) }\end{array}$ \\
\hline Pseudomonas chlororaphis PCL1606 & Rosellinia necatrix & Avocado & Yes & Yes & Tienda et al. (2020) \\
\hline Paenibacillus rhizospherae & Rosellinia necatrix & Apricot & Yes & No & Cruz et al. (2014) \\
\hline Bacillus amyloliquefaciens & Rosellinia necatrix & NA & NA & NA & Yoshida et al. (2001) \\
\hline
\end{tabular}

NA, not available.

successfully regulate $R$. necatrix pathogens (Arjona-López and López-Herrera, 2020). In another study, the antagonistic effect of $T$. harzianum against $R$. necatrix was inconsistent in greenhouses compared with laboratory evaluation results, and its efficacy was influenced by factors including root stock and soil type (Golafrouz et al., 2020). In pear orchards, dis- 
ease occurrence appears to have increased in recent years, but reports on white root rot control in pear fruit trees using antagonistic fungi are absent. However, recent studies have suggested that $T$. harzianum could be a potential antagonist against $R$. necatrix.

\section{Antagonistic Bacteria}

Several studies have utilized bacteria and their metabolites in controlling white root rot (Table 1). These antagonistic bacterial species isolated from rhizosphere, soil, and plant endophytes were investigated as biocontrol agents against R. necatrix. Yasuda and Katoh (1989) observed that Agrobacterium and Pseudomonas, isolated from the soil or roots of peach and apple, colonize and survive efficiently, and play an important role in white root rot disease control. Similarly, bacteria isolated from the soil and rhizosphere of avocado orchards displayed a bicontrol effect against $R$. necatrix (Cazorla-Lopez et al., 2001; González-Sánchez et al., 2004). Yoshida et al. (2001) used bacterial metabolites derived from Bacillus amyloliquefaciens against $R$. necatrix, which strongly inhibited its growth in vitro. Kim et al. (2019) demonstrated that Bacillus thuringiensis C25 exhibited strong antagonistic effects on mycelial growth by degrading the cell wall structures of $R$. necatrix mycelia. Recently, Tienda et al. (2020) used a microbiome study to achieve an improved understanding of natural interactions between biocontrol agents and their impact on microbial communities. They observed that Pseudomonas chlororaphis (PCL1606) exhibited the highest biocontrol efficacy, and the biocontrol activity was directly correlated with the antifungal antibiotic 2-hexyl 5-propyl resorcinol, and the modified microbial communities. Despite several reports detailing the effective biocontrol agents against $R$. necatrix, biocontrol strategies have not been currently applied to control $R$. necatrix in pear orchards. Most of the biocontrol agents have been tested in other plant systems, and most studies have focused on in vitro or confined to greenhouse experiments, and their potential under field conditions needs further verification.

\section{Virocontrol Using Mycoviruses}

Biological control utilizing viruses is called virocontrol. Mycoviruses are virus-like organisms of double-stranded RNA (dsRNA) that infect fungi and reduce the pathogenicity of host fungi to their host plants. Mycoviruses have been the subject of research interest because of their potential as BCA against plant pathogenic fungi. Mycoviruses have also been proposed for the control of R. necatrix (Matsumoto, 1998; Matsumoto et al., 2002). Since R. necatrix spreads almost clonally and exclusively through root contacts, the pathogenic $R$. necatrix can be possibly transfected by placing the inoculum containing an effective dsRNA in contact with the mycelium of the pathogen, which then transfects the pathogen and spreads within the mycelial network. Considering the presence and distribution of virus-infected fungi, approximately $20 \%$ of those collected were found to be dsRNA-positive $R$. necatrix, and presumed to be infected by mycoviruses (Arakawa et al., 2002). Several studies on Japanese, Australian, Korean, Spanish, and Israelite isolates of $R$. necatrix describe the presence of dsRNA (Arakawa et al., 2002; Arjona-López et al., 2020; Chun and Kim, 2021). Importantly, several viruses such as Mycoreovirus 3 (MyRV3), Rosellinia necatrix megabirnavirus 1 (RnMBV1), and Rosellinia necatrix megabirnavirus 2 (RnMBV2), have been shown to induce hypovirulence in the $R$. necatrix fungal host (Chiba et al., 2009; Kanematsu et al., 2004; Sasaki et al., 2016). Recently, a member of the new viral species Rosellinia necatrix hypovirus 2 (RnHV2) infecting the pathogens showed lower colony growth in vitro and lower virulence in avocado plants than in virus-free $R$. necatrix (Arjona-López et al., 2021). Similarly, co-infection of R. necatrix by Rosellinia necatrix partitivirus 10 (RnPV10) and Rosellinia necatrix virga-like virus (RnVLV) confirmed the hypovirulence of $R$. necatrix (Arjona-López et al., 2020). By utilizing the successful example of virocontrol against $R$. necatrix, biological control of white root rot in pear orchards is achievable. For this purpose, $R$. necatrix must be isolated from the target orchard, interacted with mycoviruses containing a hypovirulence factor, and placed into the soil. The new virus-carrying strain can transfer the mycovirus as a donor to pathogenic strains in an orchard (Kondo et al., 2013).

\section{Ecofriendly Methods for Disease Management}

Ecofriendly disease management methods without the use of conventional chemical fungicides or bactericides are beneficial in managing plant diseases. Orchard growers have several management options that offer effective control of the pathogen with minimal impact on the environment. This can 
be achieved by interrupting the disease cycle, plant susceptibility, or the microbial balance, causing disease reduction below the economic injury level, rather than absolute control and maintenance of crop yield. Several "ecofriendly" plant disease management methods such as soil solarization, hot water treatment, weed management, and ecological engineering are available. These methods may not achieve $100 \%$ efficiency; however, in the orchards, they will attain a level of disease reduction that is below the economic injury level.

\section{Solarization}

Solarization is a hydrothermal process in which wet soil is covered with a transparent plastic sheet to absorb solar radiation (Pérez-Jiménez, 2006). When the soil covered with a plastic sheet absorbs the radiation, the temperature of soil can increase up to $40-50^{\circ} \mathrm{C}$, which affects soil pathogen due to exposure at high temperatures. This method developed in Israel during the late 1970s, was used as an ecofriendly approach to control white root rot disease. This method has proven effective and was used successfully against $R$. necatrix in established avocado and apple tree orchards (Freeman et al., 1990; López-Herrera et al., 1995; Sztejnberg et al., 1987) and apple nurseries (Sharma and Sharma, 2002). Sztejnberg et al. (1987) reportedly achieved $75 \%$ mortality of $R$. necatrix at a soil depth of $60 \mathrm{~cm}$ after 56 days of solarization. Furthermore, López-Herrera et al. (1999) reported complete destruction of the inoculum up to a depth of $60 \mathrm{~cm}$ after 6 weeks of solarization. Along with the thermal inactivation of the pathogen, other mechanisms, such as the accumulation of volatile substances under the plastic film and the activation of soil microorganisms assist in pathogen control (Freeman et al., 1990). Moreover, when analyzing solarized soils, Sharma and Sharma (2002) observed an increased population of thermo-tolerant antagonistic microorganisms, although the total microbial population, including fungi, bacteria, and actinomycetes decreased. However, soil solarization fulfills the requirements for successfully controlling soil-borne pathogen in orchards, as the trees are not damaged, since the inoculum is controlled at a considerable depth with delayed soil reinfestation.

\section{Hot Water Treatment}

Hot water treatment is an environmentally friendly meth- od to control soil-borne diseases and offers fruit growers an alternative to chemical pesticides. Hot water treatment can be used in established orchards, to disinfect plant material used for propagation and kill the pathogen within the rhizosphere, exploiting the fact that $R$. necatrix is extremely heatsensitive. Hot water treatment was successfully used as a control strategy to prevent the spread of $R$. necatrix through infected tiger nut (Cyperus esculentus) tubers (Garcla-Jiménez et al., 2004). The pathogen was completely devitalized in tubers treated at $55^{\circ} \mathrm{C}$ for 10,20 , or $30 \mathrm{~min}$, and tubers did not show any reduction in sprouting. In field trials, hot-water treatments at $53^{\circ} \mathrm{C}$ or $55^{\circ} \mathrm{C}$ for 25 min provided good control of the disease, and normal plant development and yield were unaffected. Furthermore, Eguchi et al. (2008) dropped hot water on the rhizosphere of Japanese pear trees infested with the white root rot fungus $R$. necatrix, which eradicated the fungus from the colonized substrate when water at $35^{\circ} \mathrm{C}$ was provided for 3 days. The time required to eradicate $R$. necatrix decreased exponentially with increasing temperature and hot water treatment; white root rot mycelia on diseased roots were completely destroyed at $50^{\circ} \mathrm{C}$ and many rootlets grew after the treatment. Recently, Takahashi and Nakamura (2020) revealed the involvement of synergism between hot water and antagonism, with indigenous soil fungi such as $T$. harzianum in controlling $R$. necatrix. Furthermore, they selected commercialized Trichoderma products that enhanced soil antagonism and determined how to use them in combination with hot water to eradicate white root rot under field conditions (Takahashi et al., 2020). However, in conclusion, this environmentally safe method is applicable to orchards of fruit trees that can tolerate a minimum water temperature of $45^{\circ} \mathrm{C}$.

\section{Weeds Management in Orchards to Control Disease}

Weeds are common on the floors of pears or fruit orchards, and their roots remain alive for a certain time period even after trimming. They may serve as reservoirs for pathogens and their vectors as alternative hosts (Wisler and Norris, 2005). Sztejnberg and Madar (1980) reported that R. necatrix attacked and killed several weed species, such as Prosopis farcta, Amaranthus gracilis, and Conyza bonariensis, suggesting that weeds can promote the spread of the disease. Furthermore, Shiragane et al. (2019) observed that nine 
out of the 20 weed species collected from two pears (Pyrus pyrifolia) orchards were infested with the fungus $R$. necatrix, without exhibiting any disease symptoms. They reported that rescue grass (Bromus catharticus) facilitates the spread of R. necatrix, and some weeds may be able to supply nutrients for the mycelial growth of this pathogen in their rhizosphere. These studies suggest that weeds play an important role in the propagation of the disease in orchards. However, certain weed species can possibly inhibit or act as antagonists to the growth and spread of R. necatrix. An unpublished study by Lee (2002) observed that Poa pratensis grass had a strong inhibitory effect on the incidence of white root rot disease by sustaining the growth of antagonistic microflora. Therefore, there is an urgent need to study potential host weeds, either antagonists or spreaders, which can be strategically applied as a biocontrol agent against $R$. necatrix.

\section{Ecological Engineering for White Root Rot Disease Management}

Ecological engineering has recently emerged as an ideal example of a pest management approach that relies on the application of cultural practices that affect habitat manipulation, enhancing biological control (Nayak et al., 2018). Habitat manipulation can be achieved by creating a suitable ecological environment within the agricultural field for natural enemies by providing food resources, alternative hosts/prey, and shelter under adverse conditions. The main focus of ecological engineering is to reduce the mortality rate of natural enemies by providing supplementary resources and manipulating host plant traits for the benefit of natural biocontrol agents. There is a growing realization that soil-borne diseases can be managed with exploitation and interventions of microbes and their metabolites, in addition to selecting appropriate plant varieties. However, ecological engineering for below-ground disease management, such as white root rot caused by fungus, can be achieved by the following activities to increase the beneficial microbial population and enhance soil fertility in orchards.

1) Practices that reduce humidity beneath the canopy, through adequate pruning regimes and an adequate drainage system, treating soil with lime to increase soil $\mathrm{pH}$, and the removal of coarse woody debris, will help to control the disease and reduce the risk of infection.

2) Remove the remains of dead trees, especially their roots, and organic material that has been infected with $R$. necatrix, and burn them on-site.

3) Good soil conditions, effective drainage, balanced fertilization, and balanced growth are of major importance in preventing root infections caused by soil-borne fungal diseases.

4) Add organic matter in the form of farm yard manure, vermicompost, and crop residue, which enhances the belowground biodiversity of beneficial microbes.

5) Application of balanced dose of nutrients using biofertilizers based on soil test report.

6) Application of biofertilizers with a special focus on mycorrhiza and plant growth promoting rhizobia.

7) Application of Trichoderma harzianum/viride and Pseudomonas fluorescens for the treatment of seed/seedling/ planting materials in nurseries, and subsequent field applications.

\section{Future Prospects}

The potential of bacteria, fungi, and mycoviruses in controlling soil-borne plant diseases is enormous, yet better strategies should be developed to holistically exploit their benefits. The application of biocontrol agents at the field or orchard level is not well-characterized, and reports on their effects at the field level is limited. Currently, most studies focus on the characterization and testing of biocontrol agents in vitro or in confined greenhouse experiments, and their potential under field conditions requires further verification. Much effort should be devoted to further characterize and implement it in the field. A multi-strain consortia study of biocontrol agents, which is closer to natural conditions, than the mass application of a single microbial strain will benefit in the future. Microbiome analysis and characterization of endophytic bacteria to identify disease resistance-conferring agents will certainly play an important role in further improving biological control. Ecological engineering using multi-strain consortia can provide a new paradigm for soil-borne disease control, which can facilitate the establishment of more sustainable agricultural applications.

\section{Conflicts of Interest}

No potential conflict of interest relevant to this article was reported. 


\section{Acknowledgments}

This work was supported by a grant from the National Institute of Horticultural and Herbal Science (NIHHS) funded by the Rural Development Administration (RDA) of the Republic of Korea (PJ01448401).

\section{References}

Arakawa, M., Nakamura, H., Uetake, Y. and Matsumoto, N. 2002. Presence and distribution of double-stranded RNA elements in the white root rot fungus Rosellinia necatrix. Mycoscience 43: 21-26.

Araki, T. 1967. Soil conditions and the violet and white root rot diseases of fruit trees. Bull. Natl. Inst. Agric. Sci. Ser. C 21: 1-109.

Arjona-López, J. M. and López-Herrera, C. J. 2020. Control of avocado white root rot using non-pathogenic Rosellinia necatrix isolates combined with low concentration of fluazinam. BioControl 65: 247-255.

Arjona-López, J. M. and López-Herrera, C. J. 2021. Entoleuca sp. infected by mycoviruses as potential biocontrol agents of avocado white root rot. Eur. J. Plant Pathol. 159: 409-420.

Arjona-López, J. M., Telengech, P., Suzuki, N. and López-Herrera, C. J. 2020. Coinfection of Rosellinia necatrix by a partitivirus and a virga-like virus is associated with hypovirulence. Eur. J. Plant Pathol. 158: 111-119.

Arjona-López, J. M., Telengech, P., Suzuki, N. and López-Herrera, C. J. 2021. A moderate level of hypovirulence conferred by a hypovirus in the avocado white root rot fungus, Rosellinia necatrix. Fungal Biol. 125: 69-76.

Arjona-López, J. M., Tienda, S., Arjona-Girona, I., Cazorla, F. M. and López-Herrera, C. J. 2019. Combination of low concentrations of fluazinam and antagonistic rhizobacteria to control avocado white root rot. Biol. Control 136: 103996.

CABI. 2020. Rosellinia necatrix (dematophora root rot). URL https:// www.cabi.org/isc/datasheet/47860\#toDistributionMaps [30 May 2021].

Cazorla-Lopez, F. M., Bloemberg, G. V. and Lugtenberg, B. J. J. 2001. Biocontrol of white root rot on avocado plants using rhizobacterial strains. IOBC/WPRS Bull. 24: 79-82.

Cazorla, F. M., Duckett, S. B., Bergström, E. T., Noreen, S., Odijk, R., Lugtenberg, B. J. J. et al. 2006. Biocontrol of avocado dematophora root rot by antagonistic Pseudomonas fluorescens PCL1606 correlates with the production of 2-hexyl 5-propyl resorcinol. Mol. Plant-Microbe Interact. 19: 418-428.

Chiba, S., Salaipeth, L., Lin, Y.-H., Sasaki, A., Kanematsu, S. and Suzuki, N. 2009. A novel bipartite double-stranded RNA mycovirus from the white root rot fungus Rosellinia necatrix: molecular and biological characterization, taxonomic considerations, and potential for biological control. J. Virol. 83: 12801-12812.

Chun, J. and Kim, D.-H. 2021. Co-infection of a novel fusagravirus and a partitivirus in a Korean isolate of Rosellinia necatrix
KACC40168. Virus Genes 57: 121-126.

Cruz, A. F., de Oliveira Soares, W. R. and Blum, L. E. B. 2014. Impact of the arbuscular mycorrhizal fungi and bacteria on biocontrol of white root rot in fruit seedlings. J. Plant Physiol. Pathol. 2: 1

Eguchi, N., Tokutake, H. and Yamagishi, N. 2008. Hot water treatment of Japanese pear trees is effective against white root rot caused by Rosellinia necatrix Prillieux. J. Gen. Plant Pathol. 74: 382-389.

Freeman, S., Sztejnberg, A., Shabi, E. and Katan, J. 1990. Long-term effect of soil solarization for the control of Rosellinia necatrix in apple. Crop Prot. 9: 312-316.

Garcla-Jiménez, J., Busto, J., Vicent, A. and Armengol, J. 2004. Control of Dematophora necatrix on Cyperus esculentus tubers by hot-water treatment. Crop Prot. 23: 619-623.

Golafrouz, H., Safaie, N. and Khelghatibana, F. 2020. The reaction of some apple rootstocks to biocontrol of white root rot Rosellinia necatrix by Trichoderma harzianum in greenhouse. J. Crop Prot. 9:577-589.

González-Sánchez, M. Á., Cazorla, F. M., Ramos, C., Vicente, A. and Perez-Jimenez, R. M. 2004. Studies of soil and rhizosphera bacteria to improve biocontrol of avocado white root rot caused by Rosellinia necatrix: management of plant diseases an arthropod pests by BCAs and their integration in agricultural systems. IOBC/WPRS Bull. 27: 169-172.

González-Sánchez, M. Á., de Vicente, A., Pérez-García, A., Pérez-Jiménez, R., Romero, D. and Cazorla, F. M. 2013. Evaluation of the effectiveness of biocontrol bacteria against avocado white root rot occurring under commercial greenhouse plant production conditions. Biol. Control 67: 94-100.

Kanematsu, S., Arakawa, M., Oikawa, Y., Onoue, M., Osaki, H., Nakamura, H. et al. 2004. A reovirus causes hypovirulence of Rosellinia necatrix. Phytopathology 94: 561-568.

Khan, A. H. 1959. Biology and pathogenicity of Rosellinia necatrix (Hart.) Berl. Biologia 5: 199-245.

Kim, K., Lee, H.-Y., Bae, W., Cho, M. and Ryu, H. 2019. Functional genomic analysis of Bacillus thuringiensis $\mathrm{C} 25$ reveals the potential genes regulating antifungal activity against Rosellinia necatrix. Korean J. Mycol. 47: 417-425.

Kondo, H., Kanematsu, S. and Suzuki, N. 2013. Viruses of the white root rot fungus, Rosellinia necatrix. Adv. Virus Res. 86: 177-214.

Kulshrestha, S., Seth, C. A., Sharma, M., Sharma, A., Mahajan, R. and Chauhan, A. 2014. Biology and control of Rosellinia necatrix causing white root rot disease: a review. J. Pure Appl. Microbiol. 8: 1803-1814.

Lee, D. H. 2002. Etiology and ecology of apple white root rot, caused by Rosellinia necatrix and its biological control. Ph.D. thesis. Kyungpook University, Daegu, Korea.

Lee, D. H., Lee, S. W., Choi, K. H., Kim, D. A. and Uhm, J. Y. 2006. Survey on the occurrence of apple diseases in Korea from 1992 to 2000. Plant Pathol. J. 22: 375-380.

Lee, S. B., Chung, B. K., Jang, H. I., Kim, K. H. and Choi, Y. M. 1995. Incidence of soil-borne diseases in apple orchards in Korea. Korean J. 
Plant Pathol. 11: 132-138.

Lee, S.-H., Kwon, Y., Shin, H., Kim, I.-J., Nam, S.-Y., Hong, E. Y. et al. 2016. Dieback of apple tree by major soil borne diseases in Chungbuk province from 2013 to 2015. Res. Plant Dis. 22: 198-201.

Lee, S.-H., Shin, H., Chang, W.-B., Ryu, K.-Y., Kim, H. T., Cha, B. et al. 2020. Dieback reality of apple trees resulting from soil-borne fungal pathogens in South Korea from 2016 to 2019. Res. Plant Dis. 26: 88-94.

López-Herrera, C. J., Basallote-Ureba, M. J., Pérez-Jiménez, R. M. and Melero-Vara, J. M. 1995. Control of Dematophora necatrix and Phytophthora cinnamomi in established avocado orchards by soil solarization. In: Proceedings of the World Avocado Congress III, pp. 404-407. Tel Aviv, Israel.

López-Herrera, C. J., Pérez-Jiménez, R. M., Basallote-Ureba, M. J., Zea-Bonilla, T. and Melero-Vara, J. M. 1999. Loss of viability of Dematophora necatrix in solarized soils. Eur. J. Plant Pathol. 105: 571-576.

Matsumoto, N. 1998. Biological control of root diseases with dsRNA based on population structure of pathogens. Jpn. Agric. Res. Q. 32: 31-35.

Matsumoto, N., Nakamura, H., Ikeda, K., Arakawa, M., Uetake, Y., Okabe, l. et al. 2002. Biocontrol of root diseases for fruit trees with dsRNA-merit and perspective. IOBCMPRS Bull. 25: 61-64.

Narváez, I., Pliego Prieto, C., Palomo-Ríos, E., Fresta, L., Jiménez-Díaz, R.M., Trapero-Casas, J. L. et al. 2020. Heterologous expression of the AtNPR1 gene in olive and its effects on fungal tolerance. Front. Plant Sci. 11:308.

Nayak, S. B., Elango, K., Tamilnayagan, T. and Vinayaka, K. S. 2018. Role of ecological engineering in pest management. In: Applied Entomology and Zoology. Vol. 2, ed. by B. S. Chandel, pp. 1-18. AkiNik Publications, New Delhi, India.

Pal, J., Sharma, S. K., Devi, S., Sharma, R., Raj, H., Karn, M. et al. 2020. Screening, identification, and colonization of fungal root endophytes against Dematophora necatrix: a ubiquitous pathogen of fruit trees. Egypt. J. Biol. Pest Control 30: 112.

Pasini, L., Prodorutti, D., Pastorelli, S. and Pertot, I. 2016. Genetic diversity and biocontrol of Rosellinia necatrix infecting apple in northern Italy. Plant Dis. 100: 444-452.

Pérez-Jiménez, R. M. 2006. A review of the biology and pathogenicity of Rosellinia necatrix: the cause of white root rot disease of fruit trees and other plants. J. Phytopathol. 154: 257-266.

Pliego, C., Cazorla, F. M., González-Sánchez, M. Á., Pérez-Jiménez, R. M., de Vicente, A. and Ramos, C. 2007. Selection for biocontrol bacteria antagonistic toward Rosellinia necatrix by enrichment of competitive avocado root tip colonizers. Res. Microbiol. 158: 463-470.

Pliego, C., Kanematsu, S., Ruano-Rosa, D., de Vicente, A., LópezHerrera, C., Cazorla, F. M. et al. 2009. GFP sheds light on the infection process of avocado roots by Rosellinia necatrix. Fungal Genet. Biol. 46: 137-145.

Ruano-Rosa, D., Arjona-Girona, I. and López-Herrera, C. J. 2018. Integrated control of avocado white root rot combining low concentrations of fluazinam and Trichoderma spp. Crop Prot. 112: 363-370.

Ruano Rosa, D. and López-Herrera, C. J. 2009. Evaluation of Trichoderma spp. as biocontrol agents against avocado white root rot. Biol. Control 51:66-71.

Sasaki, A., Nakamura, H., Suzuki, N. and Kanematsu, S. 2016. Characterization of a new megabirnavirus that confers hypovirulence with the aid of a co-infecting partitivirus to the host fungus, Rosellinia necatrix. Virus Res. 219: 73-82.

Sharma, M. and Sharma, S. K. 2002. Effect of soil solarization on soil microflora with special reference to Dematophora necatrix in apple nurseries. Indian Phytopathol. 55: 158-162.

Shiragane, H., Usami, T. and Shishido, M. 2019. Weed roots facilitate the spread of Rosellinia necatrix, the causal agent of white root rot. Microbes Environ. 34: 340-343.

Sztejnberg, A., Freeman, S., Chet, I. and Katan, J. 1987. Control of Rosellinia necatrix in soil and in apple orchard by solarization and Trichoderma harzianum. Plant Dis. 71: 365-369.

Sztejnberg, A. and Madar, Z. 1980. Host range of Dematophora necatrix, the cause of white root rot disease in fruit trees. Plant Dis. 64: 662-664.

Takahashi, M. and Nakamura, H. 2020. Toothpick method to evaluate soil antagonism against the white root rot fungus, Rosellinia necatrix. J. Gen. Plant Pathol. 86: 55-59.

Takahashi, M., Tsutaki, Y. and Nakamura, H. 2020. Selection of Trichoderma products to enhance the control of loquat white root rot by hot water drip irrigation. J. Gen. Plant Pathol. 86: 419-422.

Ten Hoopen, G. M. and Krauss, U. 2006. Biology and control of Rosellinia bunodes, Rosellinia necatrix and Rosellinia pepo: a review. Crop Prot. 25: 89-107.

Tienda, S., Vida, C., Lagendijk, E., de Weert, S., Linares, I., GonzálezFernández, J. et al. 2020. Soil application of a formulated biocontrol rhizobacterium, Pseudomonas chlororaphis PCL1606, induces soil suppressiveness by impacting specific microbial communities. Front. Microbiol. 11: 1874.

Wisler, G. C. and Norris, R. F. 2005. Interactions between weeds and cultivated plants as related to management of plant pathogens. Weed Sci. 53: 914-917.

Yasuda, M and Katoh, K. 1989. Characteristics of bacteria isolated from soil and roots of fruit trees. Soil Sci. Plant Nutr. 35: 501-508.

Yoshida, S., Hiradate, S., Tsukamoto, T., Hatakeda, K. and Shirata, A. 2001. Antimicrobial activity of culture filtrate of Bacillus amyloliquefaciens RC-2 isolated from mulberry leaves. Phytopathology 91: 181-187. 